\title{
LABORATORY EVALUATION OF WITHIN-SPECIES, BETWEEN-SPECIES, AND PARTHENOGENETIC REPRODUCTION IN RETICULITERMES FLAVIPES AND RETICULITERMES VIRGINICUS ${ }^{1}$
}

\author{
By Ralph W. Howard, ${ }^{2,3}$ Eldon J. Mallette, ${ }^{2}$ \\ Michael I. Haverty, ${ }^{4}$ and Richard V. Smythe ${ }^{5}$
}

\section{INTRODUCTION}

Considerable interest currently exists regarding the reproductive strategies of social insects (Blum and Blum, 1979; Crozier, 1979). Among termites (Order Isoptera) colony foundation by alate pairs, fusion of existing colonies, splitting of existing colonies, and parthenogenesis have all been reported (Nutting, 1969). Little information is available regarding the relative importance of each of these strategies.

The genus Reticulitermes (Rhinotermitidae) contains six Nearctic and twelve Palearctic species, three of which have been critically examined for reproductive modes. Pickens (1932) and Weesner (1956) studied colony foundation of $R$. hesperus Banks by male + female dealate pairs, as well as by parthenogenesis. Buchli (1950) studied similar strategies for $R$. lucifugus Rossi. Clement (1979) studied interspecific hybridization of $R$. santonensis Feytaud and $R$. lucifugus. More limited studies on colony foundation by male + female dealate pairs of $R$. flavipes (Kollar) were conducted by Beard (1974).

Field studies with $R$. flavipes (Howard and Haverty, 1980) suggest that an important reproductive strategy for this species is colony splitting with subsequent production of numerous (several hundred) neotenic reproductives. However, sizeable alate flights are also a prominent feature of the biology of Reticulitermes spp. and

1 Manuscript received by the editor July 6, 1981.

${ }^{2}$ Forestry Sciences Laboratory, Southern Forest Experiment Station, P. O. Box 2008 GMF, Gulfport, MS 39503.

${ }^{3}$ Author to whom correspondence should be addressed.

${ }^{4}$ Pacific Southwest Forest and Range Experiment Station, P. O. Box 245, Berkeley, CA 94702.

${ }^{5}$ North Central Forest and Range Experiment Station, 1992 Folwell Avenue, St. Paul, MN 55108. 
suggest that alate-based reproductive strategies may also be important. Field studies of colony foundation by alate pairs are extremely difficult. We have accordingly chosen to investigate by laboratory studies the potential of alate based reproductive modes. We have examined incipient colony formation with males and females of the same species, males and females of different species, and pairs of conspecific females. Our results are reported here.

\section{Methods And Materials}

\section{Termites}

Unflown alates were collected from fallen logs in the De Soto National Forest in southern Mississippi. $R$. flavipes alates were collected from mid-March to early April of 1968, 1969, and 1970 (one source colony each year) and from mid-September to early October of 1967, 1968, and 1969 (one source colony each year). $R$. virginicus alates were collected in mid-April to mid-May of 1968 , 1969, and 1970 (one source colony each year). At least 500 alates/source colony were anesthetized with $\mathrm{C}_{2}(200 \mathrm{ml} / \mathrm{min})$, sexed, placed in separate petri dishes lined with moistened filter paper, and transferred to a dark incubator at $25 \pm 1^{\circ} \mathrm{C}$ for less than one week. $R$. flavipes alates to be paired with $R$. virginicus alates were held in their source wood for up to 30 days in an incubator at $15 \pm 1^{\circ} \mathrm{C}$ until $R$. virginicus alates were available. All alates were allowed to lose their wings naturally before pairing.

\section{Pairing Procedures}

Each experimental unit consisted of an $8.3-\times 12.7-\mathrm{cm}$ piece of single strength window glass to which $2.5 \mathrm{~mm} \times 1 \mathrm{~cm}$ strips of plexiglass had been glued to form a $6.3-\times 8.9-\mathrm{cm}$ rectangular cell (Howard, 1980). Washed and ovendried sand was placed in the upper third of the cell and moistened with deionized water. Two 2$\times 4-\mathrm{cm} \times 1$ - to $2-\mathrm{mm}$ weathered strips of southern pine were gently inserted about $1 \mathrm{~cm}$ apart into the border of the moistened sand. Termites were placed in the cell, the cell was closed by covering the opening with four $2.5-\times 7.5-\mathrm{cm}$ microscopic slides, and then the cell was sealed along the edges with hot paraffin. A small opening (about $1 \mathrm{~mm}$ ) was left to allow for air exchange.

Dealated termites were randomly selected, paired, and placed in an experimental unit. Each unit was examined daily during the first week and any termites caught in condensed moisture were freed. 
Also during this period dead dealates were replaced with live ones. After the first week dead dealates were removed but not replaced. Subsequent inspections were made approximately three times a week for the following month, then two times a week for 3 months, once a week for 2 months, and once every 2 weeks thereafter until the dealates were dead or the experiment was terminated. At each inspection the number of live dealates, eggs, larvae (by stage), presoldiers, and soldiers were recorded.

Seven combinations involving the following pairings were examined: (1) $R$. flavipes male $+R$. flavipies female (spring); (2) $R$. flavipes male $+R$. flavipes female (fall); (3) $R$. virginicus male + $R$. virginicus female; (4) $R$. flavipes male $+R$. virginicus female; (5) $R$. virginicus male $+R$. flavipes female; (6) $R$. flavipes female $+R$. flavipes female; and (7) $R$. virginicus female $+R$. virginicus female. Each combination was replicated a minimum of ten times per year.

\section{Determination of Larval Stage}

Larvae from six of the seven combinations were randomly selected from at least five of the experimental units in each combination and placed in Bouin's solution. Measurements were then made of the number of antennal segments and head width. These data were used for determining the instars of live larvae through the fourth stage.

\section{Summarization of Data}

For each of the seven combinations the following two kinds of data were gathered: (1) mean number of days to the first appearance of an egg, 1st-, 2nd-, 3rd-, and 4th-stage larva, presoldier and soldier; and (2) mean caste composition of incipient colonies at selected intervals. Not all colonies were established nor observed on the same days. To make the various pairings comparable, dates of establishment and observation were converted to Julian dates. Observations were then grouped by the number of days past the data of pairing. Results of pairings replicated over 2 or 3 years were combined. To simplify data summarization, observations were grouped in 3-day intervals. Because of the different times of observation, not all of the colonies were included in each 3-day interval, giving rise to fluctuations in the number of colonies included in the summarized data.

When both dealates had died, colonies were removed from the experiment. Some of the colonies remained viable for more than 2 
years. However, when the number of colonies included in any 3-day interval for any of the combinations dropped below five, we discontinued summarization of the data for that combination, since average caste compositions based on less than five colonies would have little meaning.

\section{Examination of Symbiotic Protozoa}

Fourth stage or older larvae from five of the $R$. virginicus male + $R$. flavipes female pairing and from four of the $R$. flavipes male + $R$. viginicus female pairing were examined for the presence of species-characteristic protozoa. $R$. flavipes contains mainly Dinenympha fimbriata Kirby, D. gracilis Leidy, Pyrsonympha major Powell, $P$. vertens Leidy, Spirotrichonympha flagellata (Grassi) and Trichonympha agilis Leidy. $R$. virginicus contains fewer species of protozoa, with the primary species being $D$. fimbriata, $P$. minor, $S$. flagellata, and T. agilis (Yamin, 1979).

\section{RESULTS}

\section{Egg and Larval Development}

The time to the first appearance of eggs and larval instars was rather similar for four of the seven combinations examined $(R$. flavipes male $+R$. flavipes female, spring; $R$. virginicus male $+R$. virginicus female; $R$. virginicus male $+R$. flavipes female; and $R$. virginicus female $+R$. virginicus female; see Table 1). Egg production began in these combinations about 8 to 15 days after pairing, and the first larvae were produced in about 38 to 45 days. Fourth stage larvae were present by about 75 days after pairing.

In contrast, the fall $R$. flavipes male $+R$. flavipes female combination required almost 25 days for egg production to begin and almost 60 days for the first larva to be produced. Fourth stage larvae were present by 83 days after pairing. The combination of $R$. flavipes male $+R$. virginicus female began egg production within 15 days of pairing, but only one larva was ever produced from this cross. This larva appeared normal and successfully molted twice (Table 1). Although the $R$. flavipes female $+R$. flavipes female combination was prolific in egg production, none of these eggs ever hatched.

\section{Soldier Production}

The proportion of incipient colonies producing soldiers in the 
Table 1. Mean number of days until the appearance of the first egg and first individual of an instar in incipient colonies of different parentage

\begin{tabular}{|c|c|c|c|c|c|}
\hline \multirow[b]{2}{*}{ Parentage $^{1}$} & \multirow[b]{2}{*}{ Egg } & \multicolumn{4}{|c|}{ Instar } \\
\hline & & 1 & 2 & 3 & 4 \\
\hline $\mathrm{Rf}_{0} \hat{\mathrm{C}}+\mathrm{Rf}$ (spring) & 8.1 & 38.2 & 46.1 & 52.9 & 74.7 \\
\hline $\mathrm{Rf}^{\hat{0}}+\mathrm{Rf} \propto$ (fall) & 24.8 & 59.7 & 65.5 & 73.1 & 83.3 \\
\hline $\mathrm{R} v \hat{O}+\mathrm{Rv}$ Q & 11.5 & 40.2 & 50.5 & 58.6 & 65.1 \\
\hline $\operatorname{Rf}_{\hat{o}}+\mathrm{Rv} Q$ & 15.0 & 48.5 & $60.4^{2}$ & $70.6^{2}$ & -3 \\
\hline $\operatorname{Rvô}+\operatorname{Rf} q$ & 11.7 & 42.2 & 50.5 & 57.0 & -3 \\
\hline $\mathrm{Rf}$ ㅇ + Rfㅇ & 7.0 & -4 & -4 & $-^{4}$ & -4 \\
\hline $\mathrm{Rv}$ ? + Rv우 & 14.6 & 45.2 & 57.8 & 64.6 & -3 \\
\hline
\end{tabular}

${ }^{1}$ Reticulitermes flavipes; Reticulitermes virginicus.

${ }^{2}$ Values from one experimental unit only.

${ }^{3}$ Not measured.

${ }^{4}$ No larvae ever produced.

various combinations varied from 8 to 58.8 percent (Table 2). The $R$. flavipes male $+R$. flavipes female (spring) combination produced only about one-third as many colonies with soldiers as did the $R$. flavipes male $+R$. flavipes female (fall) combination. The $R$. virginicus male $+R$. virginicus female combination, however, produced approximately the same proportion of colonies with soldiers as did the $R$. virginicus female $+R$. virginicus female combination.

\section{Temporal Colony Composition and Numbers}

The relative proportions of eggs and larvae in the $R$. flavipes male $+R$. flavipes female (spring) combination (Fig. 1A), R. virginicus

Table 2. Soldier production in incipient colonies of different parentage

\begin{tabular}{|c|c|c|c|}
\hline Parentage $^{1}$ & $\begin{array}{l}\text { Number of colonies } \\
\text { producing soldiers }\end{array}$ & $\begin{array}{l}\text { Total number } \\
\text { of colonies }\end{array}$ & $\begin{array}{l}\text { Percent of colonies } \\
\text { producing soldiers }\end{array}$ \\
\hline $\mathrm{Rf}_{\hat{0}}+\mathrm{Rf} \not$ (spring) & 14 & 69 & 20.3 \\
\hline $\mathrm{Rf}_{\hat{O}}+\mathrm{Rf}$ (fall) & 20 & 34 & 58.8 \\
\hline $\mathbf{R v o ̂}+\mathbf{R v}$ Q & 6 & 75 & 8.0 \\
\hline 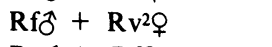 & 1 & 85 & 1.2 \\
\hline $\mathrm{Rvô}+\mathrm{RfO}$ & 22 & 85 & 25.9 \\
\hline $\operatorname{Rf}^{\hat{0}}+\operatorname{Rf}^{3} \underline{q}$ & 0 & 13 & 0 \\
\hline $\mathrm{Rvo \hat { }}+\mathrm{Rv} q$ & 2 & 18 & 11.1 \\
\hline
\end{tabular}

${ }^{1}$ Reticulitermes flavipes; Reticulitermes virginicus.

${ }^{2}$ Only one pair produced a larva.

${ }^{3}$ No eggs hatched in this crossing. 

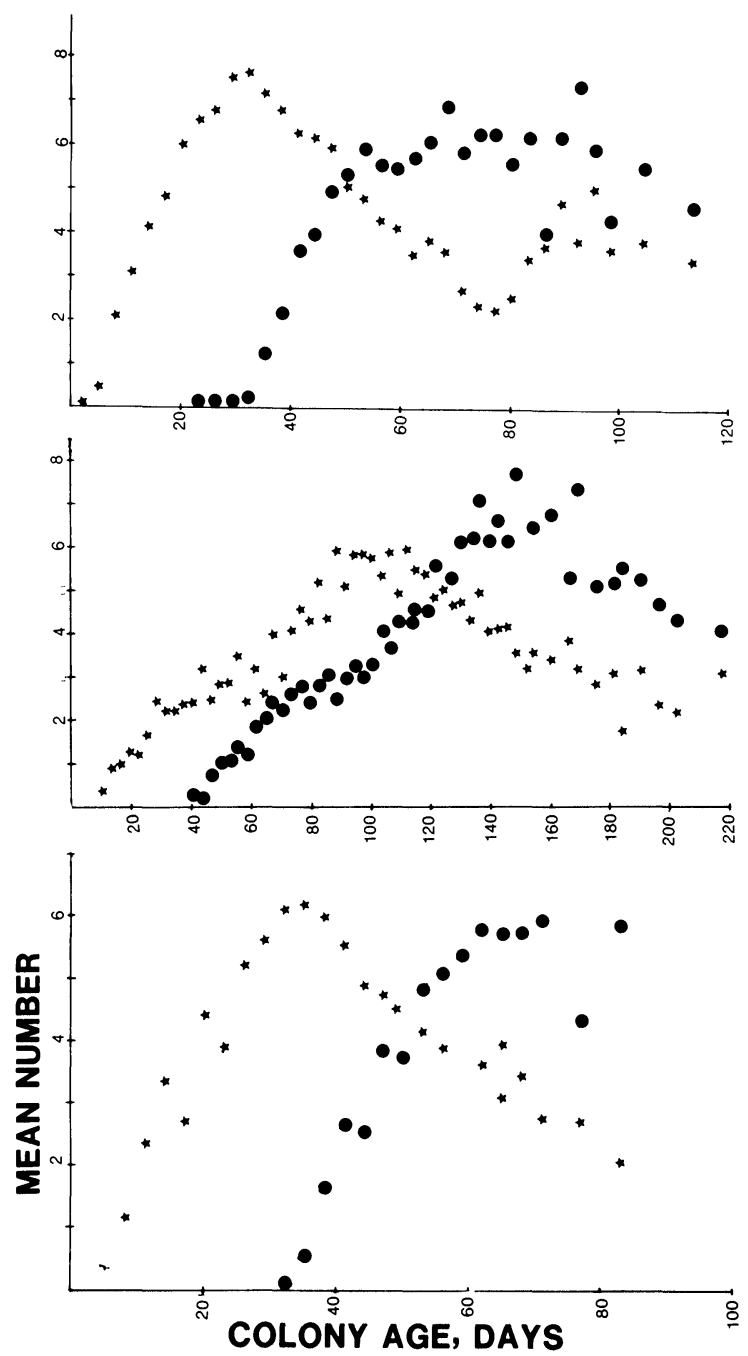

Figure 1. Mean number of eggs and larvae produced by incipient colonies headed by male and female dealates of the same species. A. R. flavipes (spring); B. $R$. flavipes (fall); C. R. virginicus. Legend: * eggs, + larvae. Each point is a mean of at least five replicates. 

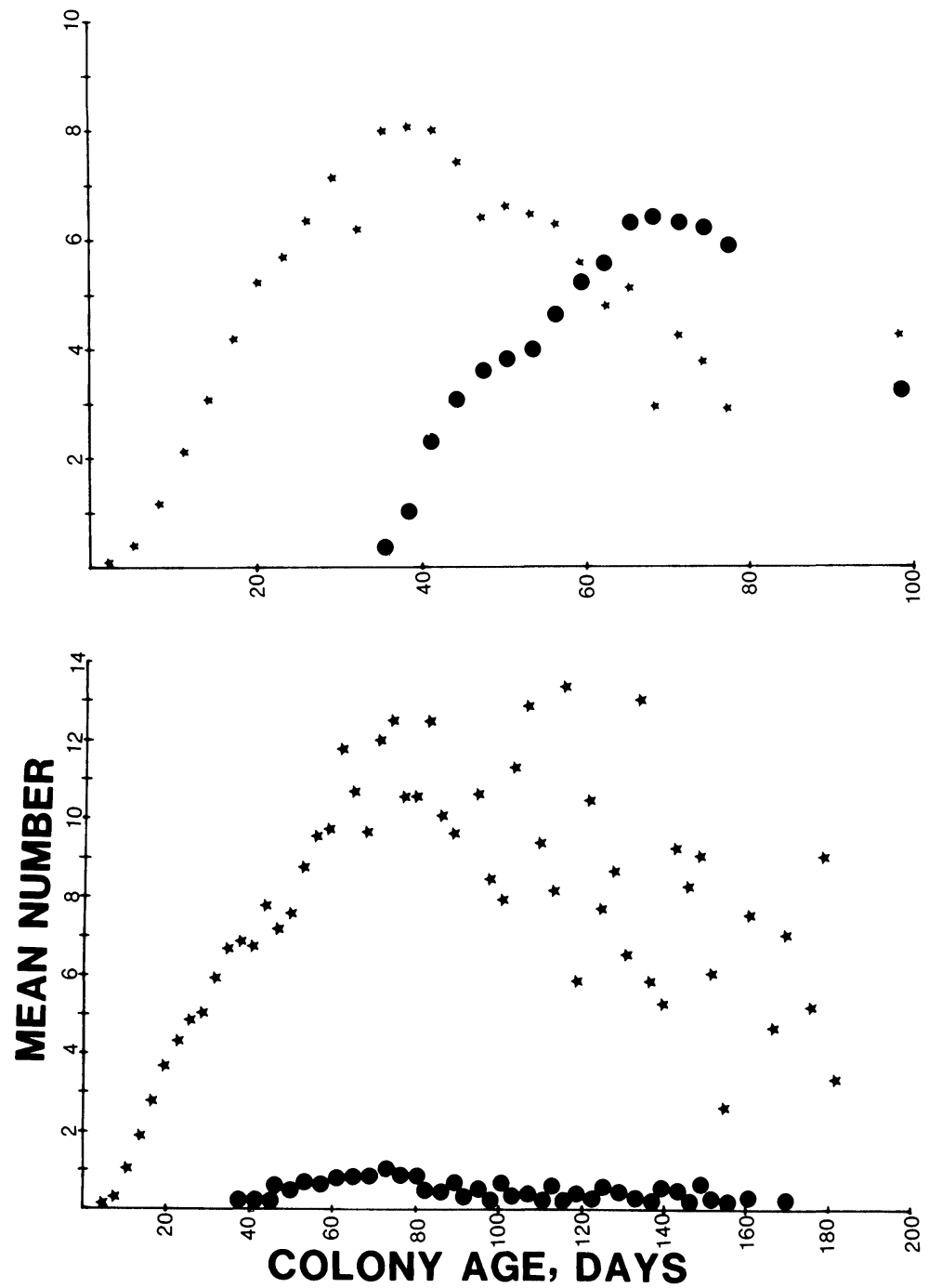

Figure 2. Mean number of eggs and larvae produced by incipient colonies headed by male and female dealates of different species. A. $R$. virginicus male $+R$. flavipes female; B. $R$. flavipes male $+R$. virginicus female. Legend: ${ }^{*}$ eggs, + larvae. Each point is a mean of at least five replicates. 

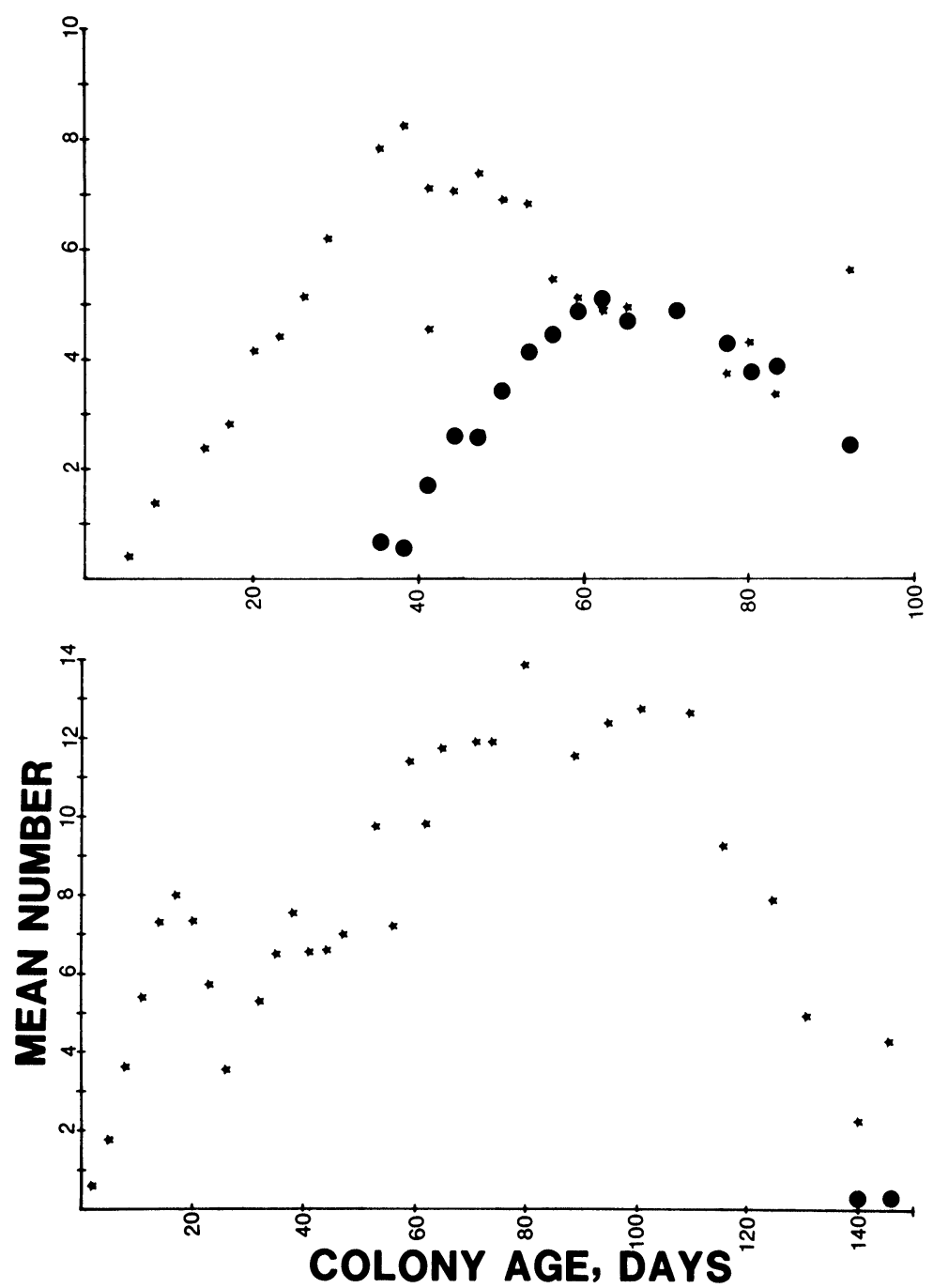

Figure 3. Mean number of eggs and larvae produced by incipient colonies headed by two female dealates of the same species. A. $R$. virginicus; $B$. $R$. flavipes. Legend: * eggs, + larvae. Each point is a mean of at least five replicates. 
male $+R$. virginicus female combination (Fig. 1C), R. virginicus male $+R$. flavipes female combination (Fig. 2A), and $R$. virginicus female $+R$. virginicus female combination (Fig. 3A) were similar at all time intervals examined. A maximum mean number of six to eight eggs were present by day 40 and a maximum mean number of six to eight larvae were present by 60 to 100 days. The fall $R$. flavipes male $+R$. flavipes female combination produced similar numbers of eggs and larvae (Fig. 1B) as the above combinations, but at a slower rate.

In contrast, the $R$. flavipes male $+R$. virginicus female combination (Fig. 2B) and the $R$. flavipes female $+R$. flavipes female combination (Fig. 3B) each produced a mean of up to 15 eggs within the first 40 to 60 days, but produced essentially no larvae.

Symbiotic Protozoa in Progeny of Between-Species Pairings

$R$. flavipes male $+R$. virginicus female: Ten larvae beyond the third instar from four experimental units were examined for protozoa. Seven larvae contained protozoa, and of these, two contained protozoa typical of $R$. flavipes, two contained protozoa typical of $R$. virginicus, and the remaining three contained mixtures of protozoa characteristics of both termite species.

$R$. virginicus male $+R$. flavipes female: Seventeen larvae from five experimental units were examined for protozoa. All larvae contained protozoa. Three contained protozoa typical of $R$. flavipes, five contained protozoa typical of $R$. virginicus, and the remaining nine contained mixtures of protozoa typical of both termite species.

\section{Discussion}

Successful incipient colony foundation by male and female dealates of $R$. flavipes and $R$. virginicus occurred readily in the laboratory. The young colonies were provided with abundant food, plentiful water, an absence of predators, and near optimum temperatures. Despite this, the growth rate of all colonies was slow, with no more than 20 to 30 larvae being produced within the first year. These results agree closely with published laboratory data on several other rhinotermitids. Buchli (1950) obtained ca. 30 individuals from $R$. lucifugus dealate pairs after 8 months, Weesner (1956) and Pickens (1932) obtained 15 to 20 individuals from $R$. hesperus 
dealate pairs after one year, and Beard (1974) obtained ca. 53 individuals from $R$. flavipes dealate pairs after one year.

King and Spink (1974) and Akhtar (1978) working with Coptotermes formosanus Shiraki and C. heimi (Wasmann), respectively, both obtained ca. 30 individuals from dealate pairs the first year. Since each of these workers utilized different temperature and rearing methods, and still obtained similar results, the observed growth rates are probably a fair approximation of that to be expected from field colonies. Such a growth rate implies that $R$. flavipes and $R$. virginicus dealate pairs (and probably other rhinotermitids as well) are K strategists (Matthew, 1976). Incipient colonies will be successful only if the dealate pairs establish nests in sites that are sparsely occupied by other members of the same species, and which possess adequate food and defense requirements necessary for slow, long term colony growth (Oster and Wilson, 1978).

Our laboratory data suggest that at least for $R$. virginicus, it might be possible for female dealates alone to parthenogenetically establish a colony with a reproductive potential equal to that of the normal male + female dealate combination. ${ }^{6}$ This finding raises the question of whether all progeny resulting from the $R$. virginicus male $+R$. virginicus female combinations are sexual offspring, or whether some fraction might have been of parthenogenetic origin.

We have also found that $R$. virginicus males readily mate with $R$. flavipes females in the laboratory, producing apparently viable progeny at rates comparable to those from same-species pairings. In contrast, the pairing of $R$. flavipes males with $R$. virginicus females results in nuptial cell construction, but only a very low rate of progeny production. We infer from our data that the progeny of the $R$. virginicus male $+R$. flavipes female combinations are true interspecific hybrids rather than parthenogenetic progeny, since paired $R$. flavipes females laid many eggs, but only one of them ever hatched. Since the larvae resulting from these mixed-species mat-

\footnotetext{
${ }^{6}$ None of the females were dissected to verify the absence of sperm. All alates however were taken from the logs before their normal flight period, and had fully developed wings which presumably rendered them incapable of copulation within the confines of the galleries of the logs. Furthermore, no instances are known of any termite species that copulate until they have flown, shed their wings, and constructed a nuptial cell. We consider it extremely unlikely that the females used in our experiments had been inseminated.
} 
ings contained protozoa typical of both parents, we also infer that the larvae engage in proctodeal feeding with both parents. We do not know whether such mixed-species pairing occurs in the field. The main flight periods of $R$. flavipes and $R$. virginicus are separated by about one month (late February to early April for $R$. flavipes and mid-April to mid-May for $R$. virginicus). But unpublished records from the Forestry Sciences Laboratory in Gulfport, Mississippi, indicate that $R$. flavipes, at least, may have flights every month of the year, rendering it at least theoretically possible for interspecific pairing to occur.

Despite the success of incipient colonies in the laboratory, their intrinsically slow growth rates raise serious questions regarding the importance of such pairs as a major means of population expansion. As noted in the introduction, our field studies (Howard and Haverty, 1980) sugget that $R$. flavipes frequently undergoes population expansion by colony fission with subsequent production of multiple neotenic reproductives. Since such new colonies presumably consist of several thousand individuals, their ability to survive should be markedly greater than that of dealate headed incipient colonies. It is, of course, possible that dealate individuals or pairs could be adopted by an established colony, but we know of no data to support such a position.

Clearly, considerably more work should be done to verify the findings of these studies. The success of intraspecific matings is not in question. The confounding results of the interspecific matings demand further cytological and experimental evaluation. The mechanisms of reproductive isolation should be clarified as well as the integrity of these two sympatric species.

\section{SUMMARY}

Incipient colony foundation in the laboratory by dealates of Reticulitermes flavipes (Kollar) and $R$. virginicus (Banks) was used to examine several possible reproductive strategies available to these sympatric subterranean termite species. Successful colony formation and progeny production occurred with pairings of $R$. flavipes males $+R$. flavipes females (from either spring or fall flights), $R$. virginicus males $+R$. virginicus females, $R$. virginicus males $+R$. flavipes females, and $R$. virginicus females $+R$. virginicus females. Few progeny resulted from pairing $R$. flavipes males $+R$. virginicus 
females, or from pairing $R$. flavipes females $+R$. flavipes females. All colony growth rates were slow, producing no more than 20 to 30 individuals within the first year.

\section{Literature Cited}

AKhTAR, M. S.

1978. Some observations on swarming and development of incipient colonies of termites of Pakistan. Pakistan J. Zool. 10(2): 283-290.

BEARD, R. L.

1974. Termite biology and bait-block method of control. Conn. Agric. Exp. Stn. Bull. 748. 19 p.

BLum, M. S., AND N. A. Blum.

1979. Sexual Selection and Reproductive Competition in Insects. Academic Press, New York. 463 p.

BUCHLI, H.

1950. Recherche sur la fondation et le developpement des nouvelles colonies chez le termite Lucifuge (Reticulitermes lucifugus Ressi [sic]). Physiol. Comp. Oecologia 2: 145-160.

Clement, J. L.

1979. Hybridation experimentale entre Reticulitermes santonensis Feytaud et Reticulitermes lucifugus Rossi. Ann. Sci. Nat., Zool. 1: 251-260.

Crozier, R. H.

1979. Genetics of sociality. P. 223-286. In Social Insects, Vol. 1. H. R. Herman (ed.). Academic Press, New York, San Francisco, and London. 437 p.

HOWARD, R. W.

1980. Effects of methoprene on colony foundation by alates of Reticulitermes flavipes (Kollar). J. Ga. Entomol. Soc. 15(3): 281-285.

Howard, R. W., aNd M. I Haverty.

1980. Reproductives in mature colonies of Reticulitermes flavipes: abundance, sex-ratio, and association with soldiers. Environ. Entomol. 9(4): 458-460.

KING, E. G., JR., AND W. T. SPINK.

1974. Laboratory studies on the biology of the Formosan subterranean termite with primary emphasis on young colony development. Ann. Entomol. Soc. Am. 67(6): 953-958.

Matthews, E. G.

1976. Insect Ecology. Univ. of Queensland Press, St. Lucia, Queensland. 226 p.

NutTing, W. L.

1969. Flight and colony foundation. P. 233-282. In Biology of Termites, Vol. 1. K. Krishna and F. M. Weesner (eds.). Academic Press, New York and London. $598 \mathrm{p}$.

Oster, G. F., AND E. O. Wilson.

1978. Caste and Ecology in the Social Insects. Princeton Univ. Press, Princeton, N. J. 352 p. 
Pickens, A. L.

1932. Distribution and life histories of the species of Reticulitermes Holmgren in California; a study of the subterranean termites with reference to (1) Zoogeography, and (2) life histories. Ph. D. Thesis. Univ. Calif.

WEESNER, F. M.

1956. The biology of colony foundation in Reticulitermes hesperus Banks. Univ. Calif. Pub. Zool. 61(5): 253-314.

Yamin, M. A.

1979. Flagellates of the orders Trichomonadida Kirby, Oxymonadida Grasse, and Hypermastigida Grassi and Foa reported from lower termites (Isoptera families Mastotermitidae, Kalotermitidae, Hodotermitidae, Termopsidae, Rhinotermitidae, and Serritermitidae) and from the wood-feeding roach Cryptocercus (Dictyoptera: Cryptocercidae). Sociobiology 4(1): 1-119. 

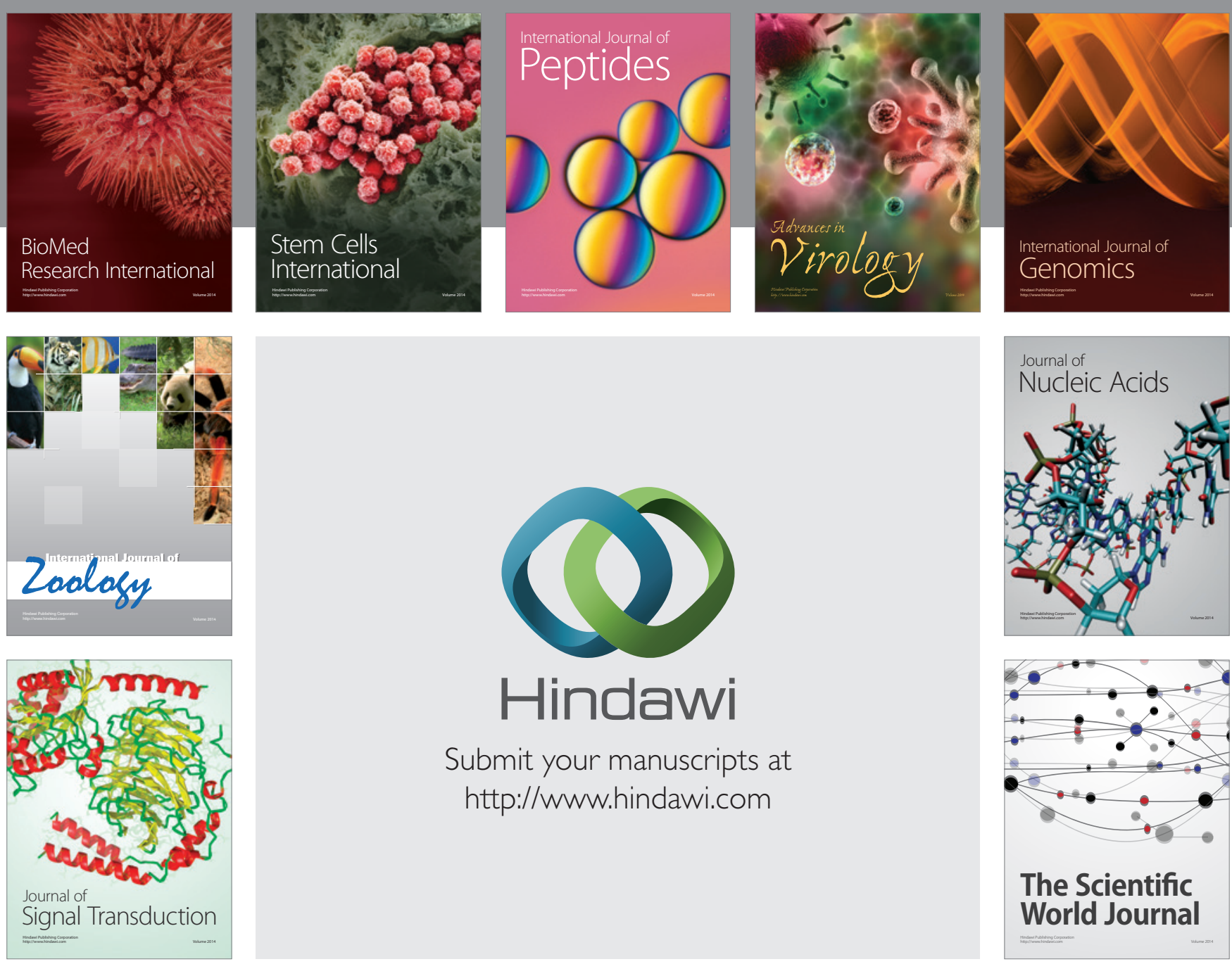

Submit your manuscripts at

http://www.hindawi.com
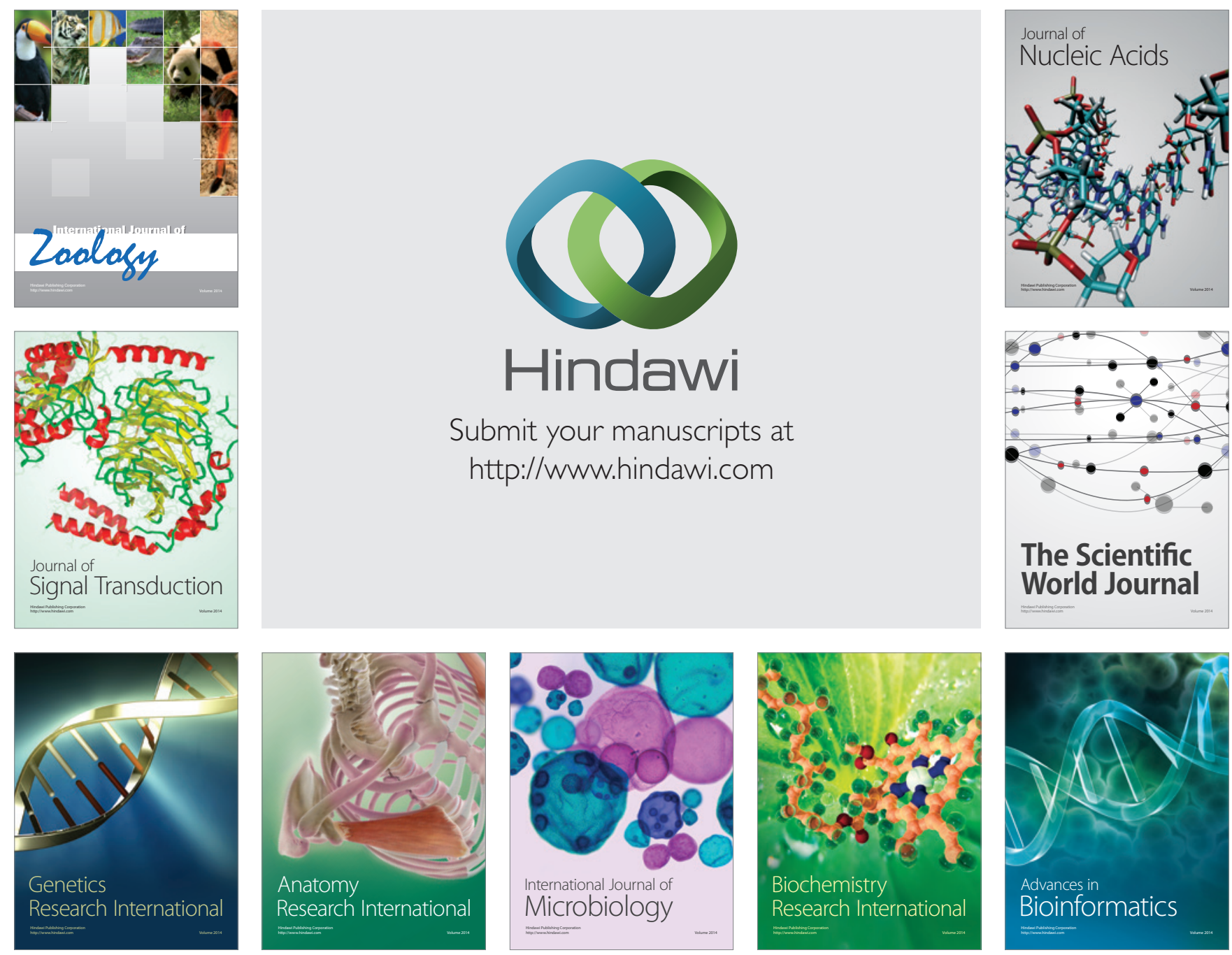

The Scientific World Journal
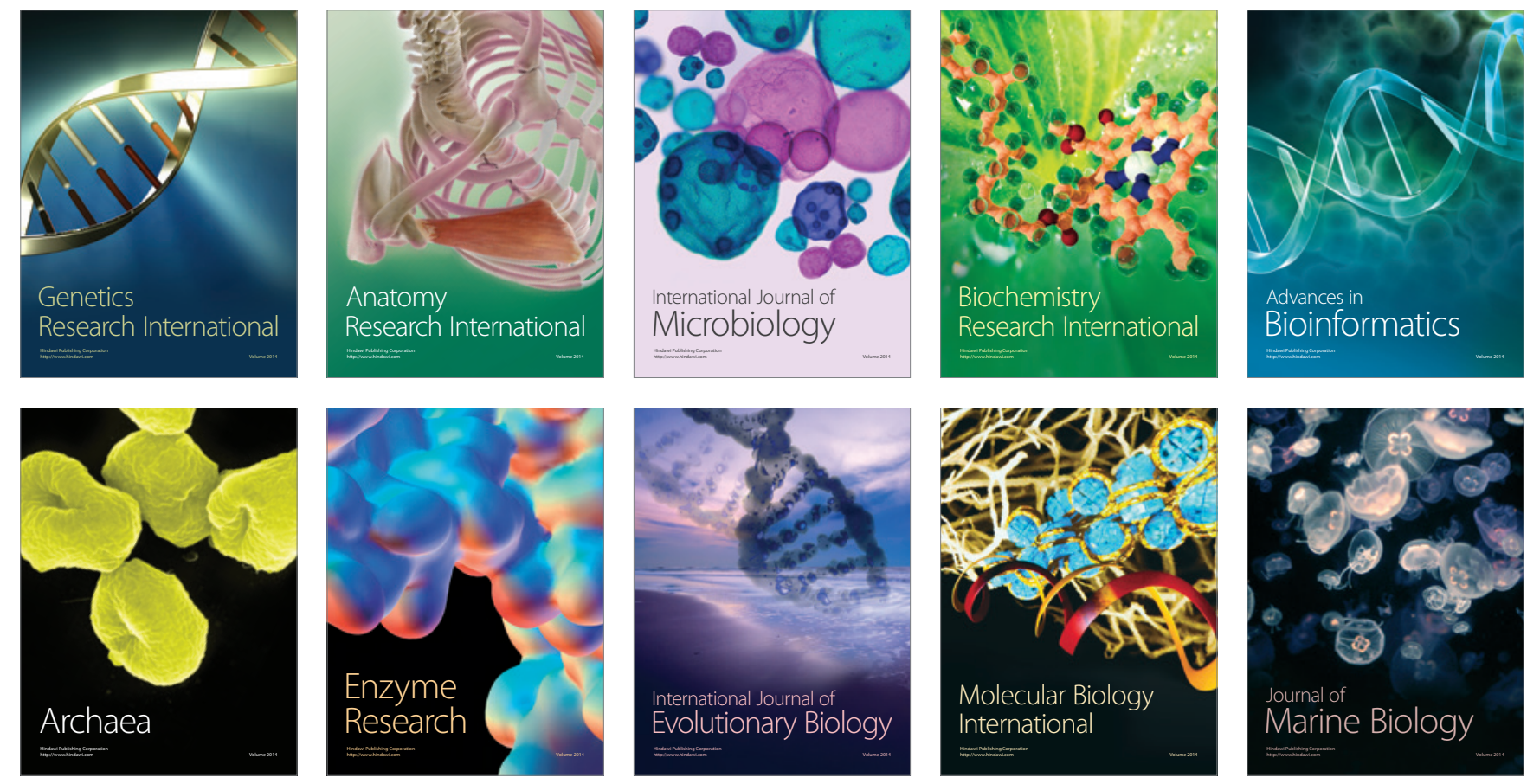